\title{
Safe and Quick Control of Hyperglycemia with Luseogliflozin in Case of High-Dose Intensive Insulin User in an Acute Ischemic Stroke Stage: A Case Report
}

\author{
Mori T*, Tanno Y, Kasakura S, Yoshioka K and \\ Nakai $\mathbf{N}$ \\ Department of Stroke Treatment, Shonan Kamakura \\ General Hospital Stroke Center, Japan \\ *Corresponding author: Takahisa Mori, Department \\ of Stroke Treatment, Shonan Kamakura General \\ Hospital, Stroke Center, Okamoto 1370-1, Kamakura City, \\ Kanagawa 247-8533, Japan
}

Received: May 30, 2017; Accepted: June 13, 2017; Published: June 29, 2017

\begin{abstract}
Introduction: Diabetes mellitus is one of major risk factors of stroke and it hasn't been established how to manage hyperglycemia safely and quickly in an acute stroke stage, particularly in cases of high-dose insulin users.

Case Presentation: A 62-year-old female undergoing high-dose intensive insulin therapy presented with numbness of the right hand. On arrival, serum glucose level was $282 \mathrm{mg} / \mathrm{dl}$ and $\mathrm{HbA} 1 \mathrm{c} 12.8 \%$, although she had daily used total dose of 66 units of insulin. Luseogliflozin, one of sodium-glucose cotransporter-2 (SGLT2) inhibitors, coupled with mild low-carbo diet started under insulin degludec of 10 units. Her fast blood glucose became $73 \mathrm{mg} / \mathrm{dl}$ in one week and discharged home.
\end{abstract}

Conclusion: Luseogliflozin coupled with mild low-carbo diet controlled hyperglycemia safely in an acute stroke stage.

Keywords: Hyperglycemia; Luseogliflozin; Acute ischemic stroke

\section{Abbreviations}

SGLT2: Sodium-Glucose Cotransporter-2; DM: Diabetes Mellitus; BMI: Body Mass Index; BW: Body Weight; SC: Subcutaneous Injection; UFAI: Ultra-Fast-Acting Insulin; LAI: Long-Acting Insulin; carbo: Carbohydrate

\section{Introduction}

Type 2 diabetes mellitus (DM) is one of major risk factors of stroke and hyperglycemia at the time of acute ischemic stroke increases the risk of hemorrhagic transformation with iv-TPA treatment and it is associated with poor clinical outcomes, longer inhospital stay, increased cost, and mortality [1-6]. However, it hasn't been established how to manage hyperglycemia safely in an acute stroke stage, particularly in cases of high-dose insulin users. Safe and effective therapy of controlling glucose level in an acute stage is required.

\section{Case Presentation}

A 62-year-old female undergoing high-dose intensive insulin therapy presented with numbness of the right hand. On arrival, her height was $158 \mathrm{~cm}$, her body weight (BW) $69 \mathrm{~kg}$, and her body mass index (BMI) $27.6 \mathrm{~kg} / \mathrm{m}^{2}$. Her serum glucose level was 282 $\mathrm{mg} / \mathrm{dl}, \mathrm{HbAlc} 12.8 \%$, urine glucose was positive and urine ketones positive on arrival, although she had daily used total dose of 66 units of insulin; subcutaneous injection (SC) of 16 units of ultrafast-acting insulin (UFAI) glulisine within 15 minutes before a meal three times a day and SC injection of 18 units of long-acting insulin (LAI) degludec at bedtime. However, she had suffered from diabetic retinopathy, diabetic neuropathy, diabetic renal dysfunction and bilateral arteriosclerosis obliterans, and had a mild ischemic stroke after all. She was obese and abdominal ultrasound showed fatty liver

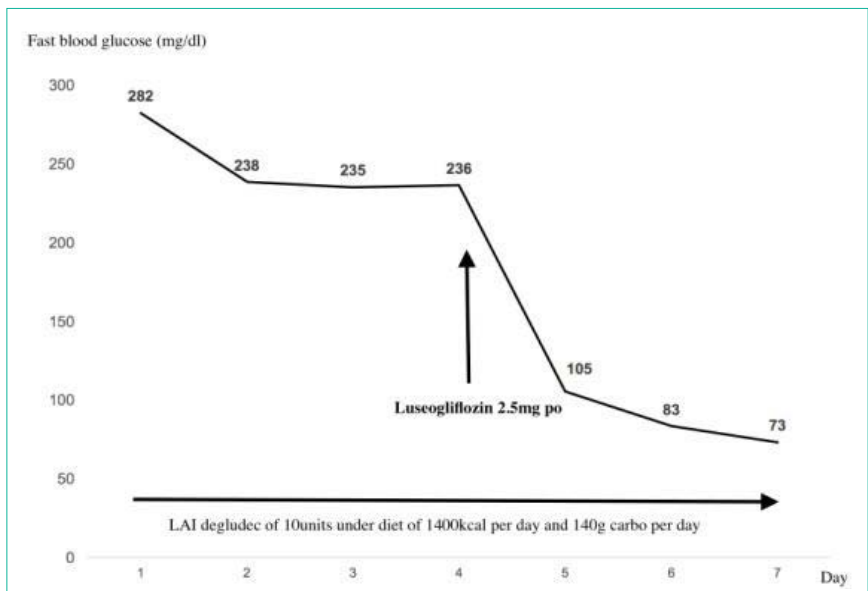

Figure 1: Relationship between day $\left(1^{\text {st }}-7^{\text {th }}\right)$ after hospitalization and fast blood glucose level $(\mathrm{mg} / \mathrm{dl})$.

on arrival, this was because she had eaten carbohydrates too much every day. Therapy she had undergone was unsuccessful in managing blood glucose level and in preventing micro- and macro-angiopathy. Immediately after hospitalization, mild low-carbo diet (1,400 kcal per day and $140 \mathrm{~g}$ of carbohydrates per day) started under LAI degludec of 10 units to control blood glucose level and luseogliflozin $2.5 \mathrm{mg}$, one of sodium-glucose cotransporter-2 (SGLT2) inhibitors was added on the 4th day (Figure 1). Intake of carbohydrates was $50 \mathrm{~g}$ at breakfast, $50 \mathrm{~g}$ at lunch and $40 \mathrm{~g}$ at dinner and she finally had 2 units of UFAI glulisine before breakfast and lunch as carbohydrate counting method. Her fast blood glucose level began to decrease remarkably after luseogliflozin and finally became $73 \mathrm{mg} / \mathrm{dl}$ in one week (Figure 1) and post-meal blood glucose level became less than $200 \mathrm{mg} / \mathrm{dl}$ under 2 units of UFAI glulisine before breakfast
Austin J Cerebrovasc Dis \& Stroke - Volume 4 Issue 4 - 2017 ISSN : 2381-9103 | www.austinpublishing group.com Mori et al. (@) All rights are reserved
Citation: Mori T, Tanno Y, Kasakura S, Yoshioka K and Nakai N. Safe and Quick Control of Hyperglycemia with Luseogliflozin in Case of High-Dose Intensive Insulin User in an Acute Ischemic Stroke Stage: A Case Report. Austin J Cerebrovasc Dis \& Stroke. 2017; 4(4): 1066 
Table 1:

\begin{tabular}{|c|c|c|}
\hline & On admission & on the $7^{\text {th }}$ day \\
\hline serum glucose level (mg/di) & 282 & 73 \\
\hline Urine $\mathrm{pH}$ & 7 & 5 \\
\hline Urine glucose & $4+$ & $4+$ \\
\hline Urine Ketone & $2+$ & $2+$ \\
\hline Arterial pH & 7.48 & 7.35 \\
\hline B.E. & -0.3 & -0.37 \\
\hline PCO2 $(\mathrm{mmHg})$ & 30.1 & 40.3 \\
\hline Total dose of insulin (units) & 66 & 14 \\
\hline Serum ketone $(\mu \mathrm{mol} / \mathrm{L})$ & & 1041 \\
\hline Body weight $(\mathrm{kg})$ & 69 & 66.6 \\
\hline
\end{tabular}

and lunch and LAI degludec of 10 units at bedtime only. Her body weight (BW) decreased from $69 \mathrm{~kg}$ to $66.6 \mathrm{~kg}$ in one week. Her numbness disappeared and she discharged home in one week under luseogliflozin $2.5 \mathrm{mg}$ po qD and total insulin dose of 14 units (Table 1). Neither acidosis nor ketoacidosis symptoms occurred, although serum ketone level increased (Table 1). Hypoglycemia of less than 70 mg/dl didn't occur, neither.

\section{Discussion}

Patients with type $2 \mathrm{DM}$ are at increased risk of cardiovascular events and cardiovascular mortality [7]. The risk of stroke in patients with type $2 \mathrm{DM}$ is increased 2 -fold compared with individuals without diabetes mellitus; the risk of recurrent stroke is also increased [8]. Trials of intensive glucose-lowering or of specific glucose-lowering agents have not been shown to significantly reduce the risk of stroke in patients with type $2 \mathrm{DM}$ even after prolonged follow-up $[9,10]$. A previous study reported that patients with type $2 \mathrm{DM}$ at high risk for cardiovascular events who received empagliflozin, the SGLT2 inhibitor, as compared with placebo, had a lower rate of the primary composite cardiovascular outcome and of death from any cause when the SGLT2 inhibitor drug was added to standard care [11]. Indeed, stroke occurs in patients with type $2 \mathrm{DM}$, indicating unsuccessful primary prevention, but effective secondary prevention hasn't been established. In addition, it hasn't been established how to control hyperglycemia in an acute stroke stage, although hyperglycemia must be controlled soon to improve clinical outcome following stroke. Therefore, our novel strategy of SGLT2 inhibitors coupled with mild calorie-and carbo-limited diet may be promising to control hyperglycemia safely and quickly in an acute stroke stage and to prevent recurrence of strokes. Her BW decreased within one week and serum ketones increased, however, acidosis didn't occur.

\section{Conclusion}

Luseogliflozin coupled with mild low-carbo diet successfully controlled blood glucose level safely in an acute stroke stage, and dramatically reduced total dose of insulin.

\section{Author's Contribution}

TM and YT treated the patient, analyzed and all authors interpreted the patient data. TM was a major contributor in writing the manuscript.

\section{References}

1. Kooten VF, Hoogerbrugge N, Naarding P, Koudstaal PJ. Hyperglycemia in the acute phase of stroke is not caused by stress. Stroke. 1993; 24: 1129 1132.

2. Weir CJ, Murray GD, Dyker AG, Lees KR. Is hyperglycaemia an independent predictor of poor outcome after acute stroke? Results of a long-term follow up study. BMJ. 1997; 314: 1303-1306.

3. Bruno A, Biller J, Adams HP, Clarke WR, Woolson RF, Williams LS, et al. Acute blood glucose level and outcome from ischemic stroke. Trial of ORG 10172 in Acute Stroke Treatment (TOAST) Investigators. Neurology. 1999; 52: $280-284$.

4. Snarska KK, Bachorzewska-Gajewska H, Kapica-Topczewska K, Wiesław Drozdowski, Monika Chorąży, Alina Kułakowska, et al. Hyperglycemia and diabetes have different impacts on outcome of ischemic and hemorrhagic stroke. Arch med sci. 2017; 13: 100-108.

5. Zonneveld TP, Nederkoorn PJ, Westendorp WF, Brouwer MC, van de Beek $\mathrm{D}$, Kruyt ND, et al. Hyperglycemia predicts poststroke infections in acute ischemic stroke. Neurology. 2017; 88: 1415-1421.

6. Gofir A, Mulyono B, Sutarni S. Hyperglycemia as a prognosis predictor of length of stay and functional outcomes in patients with acute ischemic stroke. Int J Neurosci. 2017; 1-7.

7. Scirica BM, Bhatt DL, Braunwald E, Steg PG, Davidson J, Hirshberg B, et al. Saxagliptin and cardiovascular outcomes in patients with type 2 diabetes mellitus. N Engl J med. 2013; 369: 1317-1326.

8. Sarwar N, Gao P, Seshasai SR. Diabetes mellitus, fasting blood glucose concentration, and risk of vascular disease: a collaborative meta-analysis of 102 prospective studies. Lancet. 2010; 375: 2215-2222.

9. Green JB, Bethel MA, Armstrong PW, Buse JB, Engel SS, Garg J, et al. Effect of Sitagliptin on Cardiovascular Outcomes in Type 2 Diabetes. N Engl j med. 2015; 373: 232-242.

10. Beckman JA, Creager MA, Libby P. Diabetes and atherosclerosis: epidemiology, pathophysiology, and management. JAMA. 2002; 287: 25702581.

11. Zinman B, Wanner C, Lachin JM, David Fitchett, Erich Bluhmki, Stefan Hantel, et al. Empagliflozin, Cardiovascular Outcomes, and Mortality in Type 2 Diabetes. N Engl J med. 2015; 373: 2117-2128.
Austin J Cerebrovasc Dis \& Stroke - Volume 4 Issue 4 - 2017 ISSN : 2381-9103 | www.austinpublishing group.com Mori et al. () All rights are reserved
Citation: Mori T, Tanno Y, Kasakura S, Yoshioka K and Nakai N. Safe and Quick Control of Hyperglycemia with Luseogliflozin in Case of High-Dose Intensive Insulin User in an Acute Ischemic Stroke Stage: A Case Report. Austin J Cerebrovasc Dis \& Stroke. 2017; 4(4): 1066. 